\title{
Mortality patterns of rock and slag mineral wool production workers: an epidemiological and environmental study
}

\author{
CYNTHIA F ROBINSON, ${ }^{1} \mathrm{~J}$ M DEMENT, ${ }^{2}$ G O NESS, ${ }^{1}$ AND R J WAXWEILER ${ }^{1}$ \\ From the Division of Surveillance, Hazard Evaluations, and Field Studies, ${ }^{1}$ National Institute for Occupational \\ Safety and Health, Center for Disease Control, Public Health Service, US Department of Health, Education \\ and Welfare, Cincinnati, Ohio 45202, and Division of Respiratory Disease Studies, ${ }^{2}$ Morgantown, \\ West Virginia 26505, USA
}

ABSTRACT An epidemiological and environmental study of rock and slag mineral wool production workers was undertaken at a plant that has been in operation since the early 1900s. Size characteristics of fibres produced by each process at the plant and data from industrial hygiene surveys were used to evaluate current and past exposures. These data suggest that the average historical airborne fibre concentration probably did not exceed 2.5 fibres/cc before 1935 and 1.0 fibre/cc after 1935 . A retrospective cohort mortality study was designed to assess mortality patterns. Detailed occupational histories were compiled on all plant employees. All jobs in the plant were assigned to one of eight potential exposure categories to assess the extent and severity of mineral wool exposure and the effect of other significant exposures on employee mortality. Findings included an increase in the number of deaths due to cancer of the digestive system and non-malignant respiratory disease among workers who had over 20 years' exposure to mineral wool or who had survived 20 years since their first exposure to mineral wool. These findings are not inconsistent with those of Enterline's (Symposium on Biological Effects of Mineral Fibres, Lyon, France, September 1979) in the Thermal Insulation Manufacturers' Association's mortality study of men employed in four mineral wool plants.

The overwhelming evidence ${ }^{2}$ of adverse health effects from exposure to asbestos has produced a need for substitute insulation materials to be used for energy conservation. Some of the substitute materials, however, such as mineral wool, are fibrous, and this has prompted concern that they might produce pathological effects similar to those seen after exposure to asbestos.

Mineral wool is a generic term for fibrous calcium silicates including rock wool, slag wool, and fibrous glass wool as described by Thoenen ${ }^{3}$ and Rarick and Ault. 4 Little toxicological and epidemiological research has been conducted on the chronic health effects of rock and slag mineral wool despite their widespread use for over 50 years.

Other types of fibres have been studied extensively, and all commercial forms of asbestos tested have been found to be carcinogenic in animals. ${ }^{12}$ In man,

Received 2 February 1981

Accepted 4 March 1981 occupational exposure to asbestos has been associated with an increased risk of respiratory tract cancer, mesothelioma of the peritoneum and pleura, and gastrointestinal cancer. ${ }^{12}$ It has also been associated with a raised risk of mortality due to non-malignant respiratory and cardiopulmonary diseases. ${ }^{12}$

Publications on the health effects of fibrous glass have been reviewed in two NIOSH documents. ${ }^{56}$ Included in these reviews were toxicological studies ${ }^{7} 8$ which showed that several fibrous materials produced mesotheliomas after intrapleural or intraperitoneal injection into rats. In 1977 Stanton et $a l^{9}$ published findings that correlated increasing fibre length with carcinogenic response in laboratory animals. The fibres found to produce the most carcinogenic response were those under 1.5 microns in diameter and over 8 microns in length. Although fibres outside these dimensions showed less correlation with the number of tumours, the authors did not exclude a low level response. Slag mineral wool showed a low level tumour response. Stanton et al 
concluded that all respirable fibres should be viewed with caution. More recently, Wagner ${ }^{10}$ reported producing five mesotheliomas in rats injected with both coated and uncoated rock wool fibres with diameters ranging from 0.2 to 3 microns.

Using an in-vitro cell culture system, Tilkes and Beck ${ }^{11}$ have shown a clear correlation between fibre length and cytotoxicity using crocidolite, chrysotile, and amosite fibres of differing lengths. In another similar in-vitro experiment using man-made mineral fibres, Beck and Tilkes again found a direct correlation between toxicity and fibre length (Symposium on the Biological Effects of Mineral Fibres, Lyon, IARC, 25-27 September 1979). Most experimental inhalation studies of fibres other than asbestos have been negative; however, Johnson and Wagner ${ }^{12}$ recently reported focal fibrosis in rats exposed via inhalation to several fibres, including rock wool. Wagner et al $^{10}$ exposed rats by inhalation to Canadian chrysotile, glass microfibre, and rock wool and glass wool with and without resin. In all of the exposed groups evidence of a reaction to dust was found; but there was less reaction to all the man-made mineral fibres than to chrysotile asbestos.

In 1934 a chest $x$-ray survey ${ }^{13}$ of 183 active employees in the plant under study found no cases of pneumoconiosis. A follow-up $x$-ray survey ${ }^{13}$ in 1943 found "exaggerated linear markings" in roughly half of the workers and of a control group. Enterline ${ }^{14}$ carried out a retrospective cohort mortality study of 7049 men who had worked one year or more in one of eight US plants producing man-made mineral fibres. Standardised mortality ratios for nonmalignant respiratory disease, heart disease, and cancer of the digestive system were found to be raised but were not statistically significant for men who had survived 20 years or more since first exposure. The SMR for respiratory cancer was not raised.

\section{Plant selection and description}

The present study began with a telephone survey of all mineral wool plants found in a trade list of manufacturers. Subsequently, five of the larger, older plants were visited to evaluate exposures and work history records. Of these five, a Midwestern plant was selected for study because: (1) it had been in operation at the present location since 1897 and had maintained adequate personnel records since 1928 , thus allowing selection of a study cohort with a long latency potential; (2) it had a large work force averaging 250 workers; and (3) only two individuals in the study population were ever exposed to asbestos at the plant (W B Reitze, personal communication, 3 January 1975).

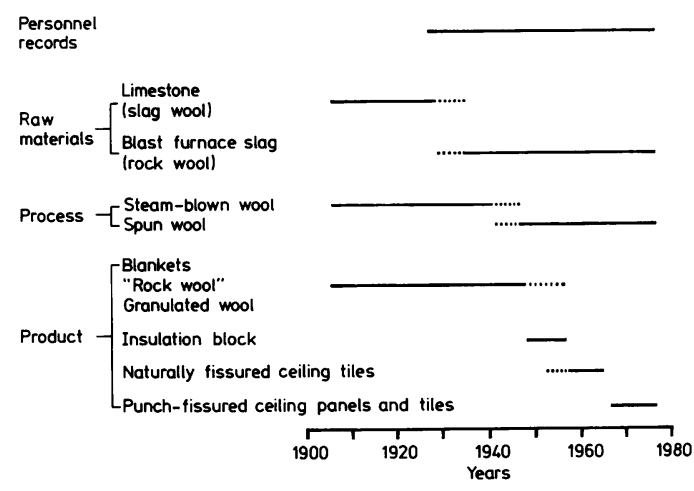

Fig 1 Personnel records, raw material, and process and product changes at mineral wool plant studied.

The raw material, process, and product changes at the plant over the period are described in fig 1 . Limestone, mined in the area, was first used in 1907 as the basic raw material to produce rock wool. In the 1930s blast furnace and phosphate slag were used as new materials until 1940, when they completely replaced limestone. Thus the production of rock wool was supplanted by slag wool.

A steam-blowing process to form fibres was used before 1940, resulting in a wide distribution of fibre diameters and lengths. Between 1940 and 1948 this process was gradually replaced by a spinning process that formed more consistent fibre sizes.

Several different products have been manufactured at this plant over the study period (fig 1). Until the mid-1950s there were three main products: insulation blankets, granulated blowing wool insulation, and flat sheet compressed insulation. The insulation blankets, flat sheets, and granulated wool were composed of mineral wool with only small quantities of binder material; therefore, there were few other exposures. In 1967 the major production at this plant was changed from insulation to compressed acoustic ceiling tiles containing slag wool and clay binders. Since 1950 no products involved significant exposures to known toxic materials except perhaps the free crystalline silica contained in the clay used to produce acoustic ceiling tiles after 1967 .

\section{Industrial hygiene}

\section{METHODS}

An industrial hygiene study was conducted at this plant in 1975 to evaluate exposure to fibres. Personal and stationary area samples were collected on openfaced, $37 \mathrm{~mm}$ diameter, Millipore type AA $(0.8 \mu \mathrm{m}$ pore size) membrane filters at a calibrated flow rate of 2 litres a minute with sample periods for individual 
samples ranging from 30 minutes to about two hours. Filters were changed periodically during the work shift so that eight-hour time-weighted exposures were estimated. Samples ${ }^{2}$ were analysed by simultaneously counting fibres and determining their diameter and length using phase contrast optical microscopy at a magnification of $430 \times$. In addition to optical microscopic analyses about $10 \%$ of the fibre samples were randomly selected after grouping by operation and analysed by transmission electron microscopy to determine airborne fibre diameters and lengths using methods described by Zumwalde et al. ${ }^{15}$

Bulk samples of the mineral wool fibres produced by the spinning process during the current study were collected. With the company's co-operation, a bulk sample of the mineral wool produced by the earlier steam-blowing process was also obtained. To determine whether the proportion of potentially respirable fibres differed between the two processes, bulk sample fibre diameter distributions were compared after sizing over 300 randomly selected fibres using phase contrast microscopy.

\section{RESULTS}

The 127 individual spun fibre samples collected were used to calculate time-weighted-average exposures for each worker sampled. Summaries of the airborne fibre concentrations and size characteristics are given in tables 1 and 2.

The highest concentration observed for any single airborne sample was slightly over 2 fibres/cc. Individual time-weighted-average exposures ranged from 0.10 to 1.95 fibres/cc with an overall timeweighted-average exposure for the plant of roughly 0.6 fibres/cc.

The airborne fibre size measurements by optical microscopy (table 2) showed count median diameters of the spun mineral wool fibres to range from $1 \cdot 7$ to $2.7 \mu \mathrm{m}$ and count median lengths to range from 6.8

Table 1 Summary of airborne fibre concentrations for mineral wool plant studied (fibres/cc)

\begin{tabular}{lll}
\hline Mean* concentration measurement & $\pm S E$ & Range \\
\hline Individual dust samples & - & $0 \cdot 10-2.04$ \\
Time-weighted-average exposures & $0.60 \pm 0.06$ & $0 \cdot 10-1.95$ \\
\hline
\end{tabular}

${ }^{*}$ Concentrations are for fibres of all lengths.

Table 2 Summary of airborne fibre size characteristics for mineral wool plant studied

\begin{tabular}{lccc}
\hline Size parameter & $\begin{array}{l}\text { Median } \\
\text { value for } \\
\text { plant }\end{array}$ & $\begin{array}{l}\text { Range for } \\
\text { individual } \\
\text { workers }\end{array}$ & $\begin{array}{c}\text { Geometric } \\
\text { standard } \\
\text { deviation }\end{array}$ \\
\hline Count median diameter $(\mu \mathrm{m})$ & $2 \cdot 2$ & $1 \cdot 7-2 \cdot 7$ & $1 \cdot 4-2 \cdot 2$ \\
Count median length $(\mu \mathrm{m})$ & $16 \cdot 0$ & $6 \cdot 8-24 \cdot 8$ & $1 \cdot 9-4 \cdot 5$ \\
\hline
\end{tabular}

Geometric standard deviation based on fitting a log-normal distribution to the fibre size data by probit analysis.

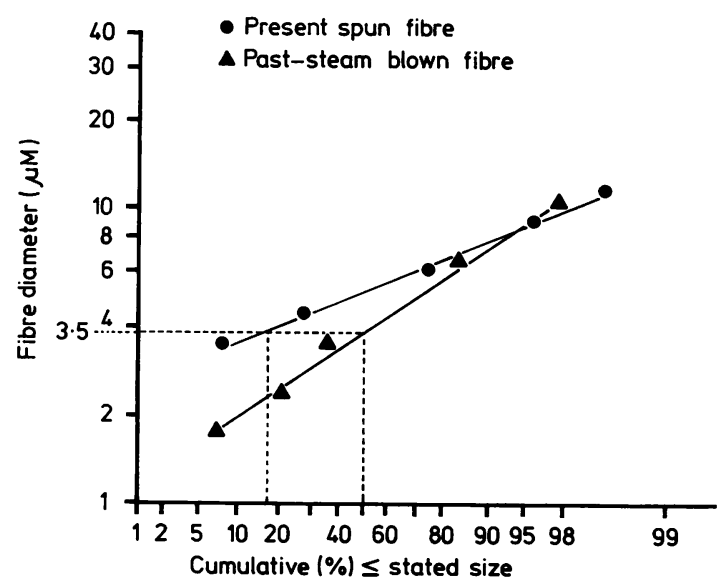

Fig 2 Diameter distributions for bulk samples of fibres produced before 1940 by steam-blower process.

to $24.8 \mu \mathrm{m}$ for the various workers sampled. There appeared to be no clear relationship between airborne fibre size and plant operation. About $75 \%$ of all airborne fibres were smaller than $3.5 \mu \mathrm{m}$ in diameter. Transmission electron microscopic inspection showed that fewer than $2 \%$ had diameters smaller than $0.5 \mu \mathrm{m}$.

The diameter distributions for the bulk samples of fibres produced before 1940 by the steam-blower process are shown in fig 2 . As seen in this figure, the distribution of diameters for the earlier steam-blown fibres is considerably broader than for the currently spun fibres. The median fibre diameter in the parent material for the earlier steam-blown fibres was estimated to be $3.6 \mu \mathrm{m}$ compared with $5.1 \mu \mathrm{m}$ for currently spun fibres, this difference being statistically significant $(p<0.05)$. Even for the steam-blown fibres, however, fewer than $2 \%$ were under $0.5 \mu \mathrm{m}$ in diameter when analysed by electron microscopy.

All airborne fibre size data for this plant were pooled to estimate pulmonary and gastrointestinal fibre deposition using the model described by Harris ${ }^{16}$ and Dement and Harris. ${ }^{17}$ It was estimated using this model that roughly $3 \%$ of all airborne fibres from the spinning process would be deposited in the pulmonary spaces while about $60 \%$ would be cleared to the gastrointestinal tract. Owing to the greater proportion of small diameter fibres from the earlier steam-blowing process, pulmonary deposition may have been slightly higher.

\section{PAST EXPOSURES AND EXPOSURE \\ CLASSIFICATIONS}

All jobs in the plant were assigned to one of eight potential exposure categories based on observations made during the industrial hygiene study and 
knowledge of past operations. The purpose of this stratification was two-fold: firstly, to eliminate dilution of the mineral wool exposed cohort with other workers (shipping, quality control, and office personnel) who had little or no exposure to mineral wool fibres and, secondly, to separate workers who may have experienced other significant exposures but not much mineral wool exposures, such as mining and cupola area workers. A summary of the categories of exposure and potential exposures is shown in table 3 . Workers classified in category 3 (production) are the main interest of this study since they received the greatest exposures to mineral wool fibres.

There have been numerous process and control changes likely to have affected exposure levels, and the lack of historic exposure data makes it impossible to generate reliable point estimates for past fibre exposure levels. The most important changes include: (1) installation of engineering controls in many plant operations in about 1935 , (2) changing from the steam blowing to the spinning process for fibre formation in about 1948, and (3) changing from the production of mineral wool insulation product to the production of acoustic ceiling tiles containing clay binders in 1967.

The only historic exposure data available for this plant were published by Carpenter and Spolyar ${ }^{18}$ in 1945 , who reported impinger dust counts taken in 1935 to range from 12 to 26 million particles per cubic foot of air (MPPCF). After improvements in dust controls made in 1935 exposures were reduced to 5-10 MPPCF. A direct conversion from impinger to fibre counts is not possible; however, Esmen et al ${ }^{19}$ estimated a rough

Table 3 Categories of exposure and potential exposures

\begin{tabular}{|c|c|c|}
\hline Category & Description & $\begin{array}{l}\text { Potential exposures } \\
\text { during study period }\end{array}$ \\
\hline 1 & $\begin{array}{l}\text { Jobs in limestone quarry, ore } \\
\text { processing, or zeolite processing }\end{array}$ & $\begin{array}{l}\text { Limestone dust, free } \\
\mathrm{SiO}^{2} \text {, zeolite dust }\end{array}$ \\
\hline 2 & $\begin{array}{l}\text { Jobs in hot end of process } \\
\text { including handling of ores, } \\
\text { charging cupola, shot disposal }\end{array}$ & $\begin{array}{l}\text { Metal fumes, CO } \\
\text { sulphates, PNAs }\end{array}$ \\
\hline 3 & $\begin{array}{l}\text { Jobs in mineral wool production } \\
\text { or production of products } \\
\text { containing mineral wool including } \\
\text { first line foreman }\end{array}$ & $\begin{array}{l}\text { Mineral wool } \\
\text { asphalt, bentonite, } \\
\text { free } \mathrm{SiO}^{2}\end{array}$ \\
\hline 4 & $\begin{array}{l}\text { Machine shop, maintenance, } \\
\text { housekeeping, and service } \\
\text { personnel. Also powerhouse } \\
\text { workers }\end{array}$ & $\begin{array}{l}\text { Some exposure to } \\
\text { most materials }\end{array}$ \\
\hline 5 & Shipping and receiving personnel & $\begin{array}{l}\text { Occasional exposure } \\
\text { to most materials }\end{array}$ \\
\hline 6 & $\begin{array}{l}\text { Laboratory and quality control } \\
\text { personnel }\end{array}$ & $\begin{array}{l}\text { Minimal exposures } \\
\text { Minimal exposures }\end{array}$ \\
\hline $\begin{array}{l}7 \\
8\end{array}$ & $\begin{array}{l}\text { Office and management personnel } \\
\text { Workers with incomplete } \\
\text { employment histories }\end{array}$ & Unknown \\
\hline
\end{tabular}

PNA = Polynuclear aromatic hydrocarbons from coke combustion. conversion of $0 \cdot 1$ fibre/cc per MPPCF. Using this approximation, fibre exposures until 1935 would be 1.2 to 2.5 fibres/cc and 0.5 to 1.0 fibres/cc after dust control improvements in 1935 . This latter value of 0.5 to 1.0 fibres/cc is representative of typical exposures until 1948, when the steam-blowing process was discontinued.

For the period 1948-67, no historic exposure data are available. Reasonable bounds for exposures during this period, however, may be estimated by using exposure data obtained from studies of similar mineral wool production operations with varying degrees of engineering control. Conditions in those plants that currently have poor control measures may approximate the upper bounds of historic exposures in the plant under study. Two large scale studies $^{2021}$ of environmental conditions in mineral wool facilities have recently been published. For plants producing insulation similar to that produced in the plant under investigation between 1948 and 1967 , average concentrations observed for production operations ranged from about $0 \cdot 1$ to $0 \cdot 3$ fibres $/ \mathrm{cc}$. Exposures increased slightly in 1967, when the production of acoustic ceiling tiles began, because cutting operations that generated more dust were necessary.

Based on available exposure data from this plant and data obtained for similar operations, the following approximations appear to be reasonable bounds for average fibre exposures for workers in mineral wool production (category 3) during the study period:

until 1935-1.2-2.5 fibres/cc;

1935-48-0.5-1.0 fibres/cc;

1948-67-0.1-0.3 fibres/cc;

1967-74-0.5-0.7 fibres/cc.

It is noteworthy that past exposures were estimated not to be high even with the general lack of controls. This is consistent with observations made by most current studies and may be attributed to the large diameter of mineral wool fibres and their ability to settle rapidly when dispersed. By contrast with asbestos, mineral wool fibres do not fracture along their length to produce small diameter and potentially more respirable fibres.

\section{Epidemiological study}

\section{METHODS}

All employment records of the study plant were microfilmed. For the 3732 individuals who had ever worked at the plant, detailed work histories of departments, job titles, and dates of specific jobs held by each employee were coded. Subsequently, a study cohort was selected to exclude all workers who had under one year of employment. Since environmentally 
induced chronic disease usually takes several decades to become apparent clinically, the study cohort was further restricted to workers having any part of their employment between 1 January 1940 and 31 December 1948. The former year was chosen because of the difficulty of tracing employees who left before 1940 , since social security numbers were not in extensive use before then. The latter year, 1948, was selected because it was the last year, by company estimates, that workers could have been exposed to the more variable diameter steam-blown mineral wool fibres.

The 596 workers who met the cohort definition were followed up from their last date of employment until 31 December 1974. Vital status was determined through records maintained by various government agencies, directories, and other sources for over $98 \%$ of the study cohort.

Death certificates were obtained for the known dead, and underlying causes of death were interpreted by a diagnostician according to the Revision of the International Classification of Diseases, adapted (ICDA), in effect at the time of death. The codes were then converted into the corresponding seventh revision codes.

A modified life table based on the Cutler-Ederer ${ }^{22}$ technique was used to obtain person-years at risk of dying by race and sex in five-year calendar time periods, five-year age groups, five-year exposure groups, and five-year latency (the period since first employment at the plant) groups. Since the cohort was limited to employees who had had at least one year of employment, person years at risk began either at one year after first date of employment or on 1 January 1940, whichever came later. Individuals with unknown vital status were assumed to be alive on 31 December 1974. In addition, one individual known to be dead, but for whom no death certificate was available, was assumed to have died from an unknown cause.

Analyses were conducted on the entire study group and then on each of eight exposure category subcohorts. Workers were included in a subcohort if they worked for at least one year in the corresponding exposure category described in table 3 . Therefore it is possible for one person to be included in more than one exposure category subcohort. The observed number of deaths in the study cohort was compared with the number expected as derived from sex, age, race, calendar-time, and cause-specific US mortality rates. The statistical significance of the number of deaths observed versus the number expected was tested using the Poisson distribution. ${ }^{23}$ SMRs were calculated by dividing the number of observed deaths by the number of expected deaths and multiplying by 100 . Exact $p$ values for the observed versus the expected frequencies and approximate confidence limits for the SMRs, are presented in the tables. SMRs were not calculated and statistical significance was not determined when both the observed and expected deaths were fewer than five.

\section{RECORD VERIFICATION}

To estimate the completeness of the cohort identified from the plant records, an independent verification based on a three-year $(1946,1953,1960)$ sample of Internal Revenue Service (IRS) Employers' Quarterly Earnings Reports was undertaken using the method described by Marsh. ${ }^{24}$ Three percent of the sample was found to have been missed during original microfilming, and an additional $10 \%$ of the sample could not be identified or located by the company.

\section{RESULTS}

Using the modified life table analysis, 16516 person years at risk of dying were accumulated

Table 4 Cause-specific deaths among white men employed in a rock and slag mineral wool production and manufacturing facility

\begin{tabular}{|c|c|c|c|c|c|c|}
\hline Cause of death & $I C D A^{*}$ & Observed deaths & Expected deaths & $S M R$ & $p$ value ${ }^{25}$ & $\begin{array}{l}\text { Approximate } 90 \% \\
\text { confidence limts } \\
\text { on the SMR }\end{array}$ \\
\hline Malignant neoplasms & $140-205$ & 36 & $35 \cdot 5$ & 102 & 0.46 & $(75-134)$ \\
\hline Digestive system & $150-159$ & 15 & $11 \cdot 5$ & 130 & $0 \cdot 19$ & $(80-201)$ \\
\hline Bronchus and lung & $162-163$ & 9 & $10 \cdot 1$ & 89 & 0.45 & $(46-155)$ \\
\hline Other and unspecified & $\begin{array}{l}140-149,156 \mathrm{~B} \\
165,170-205\end{array}$ & 12 & $13 \cdot 9$ & 86 & $0 \cdot 39$ & $(50-140)$ \\
\hline Diseases of central nervous system & $330-334,345$ & 15 & $16 \cdot 3$ & 92 & 0.44 & $(57-142)$ \\
\hline Diseases of heart & $400-443$ & 93 & $95 \cdot 6$ & 97 & 0.40 & $(81-116)$ \\
\hline Non-malignant respiratory disease & $470-527$ & 10 & 10.9 & 92 & 0.47 & $(50-156)$ \\
\hline Influenza, pneumonia, bronchitis & $470-502$ & 2 & $6 \cdot 1$ & 33 & 0.06 & (6-103) \\
\hline Other respiratory disease & $510-527$ & 8 & $4 \cdot 8$ & 167 & $0 \cdot 11$ & $(83-301)$ \\
\hline Residual causes, unknown & & 30 & $47 \cdot 0$ & 64 & $0.0 c 4$ & $(46-87)$ \\
\hline Total & & 184 & $205 \cdot 3$ & 90 & 0.07 & $(79-101)$ \\
\hline
\end{tabular}

*7th Revision of International Lists of Diseases and Causes of Death, adapted. 
Table 5 Observed and expected deaths by selected cause among white men employed in a rock and slag mineral wool production and manufacturing facility by the eight work history exposure categories

\begin{tabular}{|c|c|c|c|c|c|c|c|c|}
\hline \multicolumn{3}{|c|}{ Exposure categories } & \multirow{2}{*}{$\begin{array}{c}\begin{array}{l}\text { All } \\
\text { deaths }\end{array} \\
2\end{array}$} & \multirow{2}{*}{$\begin{array}{l}\begin{array}{l}\text { All } \\
\text { cancer }\end{array} \\
0\end{array}$} & \multirow{2}{*}{$\begin{array}{l}\begin{array}{l}\text { Digestive } \\
\text { cancer }\end{array} \\
0\end{array}$} & \multirow{2}{*}{$\begin{array}{l}\begin{array}{l}\text { Lung } \\
\text { cancer }\end{array} \\
0\end{array}$} & \multirow{2}{*}{$\begin{array}{l}\begin{array}{l}\text { Non-malignant } \\
\text { respiratory } \\
\text { disease }^{*}\end{array} \\
1\end{array}$} & \multirow{2}{*}{$\begin{array}{l}\text { Total person } \\
\text { years }\end{array}$} \\
\hline 1 & Ore & Obs & & & & & & \\
\hline & & SMR & - & - & - & - & - & 252 \\
\hline \multirow[t]{2}{*}{2} & Hotend & Obs & 28 & 6 & 1 & 3 & 0 & \\
\hline & & SMR & 83 & 98 & - & - & - & 2568 \\
\hline \multirow[t]{2}{*}{3} & Production & Obs & 149 & 27 & 12 & 7 & 6 & \\
\hline & & SMR & 90 & 93 & 128 & 88 & 158 & 13851 \\
\hline \multirow[t]{2}{*}{4} & Maintenance & Obs & 50 & 13 & 5 & 2 & 3 & \\
\hline & & SMR & 83 & 120 & 139 & - & - & 3431 \\
\hline \multirow[t]{2}{*}{5} & Shipping and receiving & Obs & 7 & 2 & 1 & 1 & 1 & \\
\hline & & SMR & 117 & - & - & - & - & 696 \\
\hline \multirow[t]{2}{*}{6} & Laboratory quality control & Obs & 5 & 1 & 1 & 0 & 0 & \\
\hline & & SMR & 62 & - & - & - & - & 501 \\
\hline \multirow[t]{2}{*}{7} & Office and management & Obs & 22 & 8 & 5 & 1 & 1 & \\
\hline & & SMR & 74 & 154 & 227 & - & - & 1576 \\
\hline \multirow[t]{2}{*}{8} & Unknown & Obs & 26 & 8 & 2 & 2 & 3 & \\
\hline & & SMR & 74 & 145 & - & - & - & 1523 \\
\hline
\end{tabular}

*After excluding influenza, bronchitis, and pneumonia.

until 31 December 1974. Among the 596 study cohort members 188 deaths occurred. The cause of death was ascertained for all but one man. Four war deaths (but not their person years at risk) were excluded from the study cohort, leaving 184 .

The 184 observed deaths in table 4 were slightly fewer than expected from US death rates. None of the cause-specific excesses or deficits was statistically significant, although the numbers of deaths due to cancer of the digestive system and non-malignant respiratory disease after excluding influenza and pneumonia were increased.

The largest exposure category subcohort (table 5) was mineral wool production. The second largest was maintenance, which also entailed some exposure to mineral wool. The remaining six subcohorts included fewer than 50 deaths.

Increased SMRs were observed for digestive cancer for three subcohorts: production, office and management, and maintenance. These excesses accounted for the increased SMRs seen for all deaths from cancer in these same subcohorts. Three of the five office and management workers who died of cancer of the digestive system had also worked for over five years in mineral wool production. Furthermore, examination of the maintenance and office subcohorts showed no trends by latency for either cancer of the digestive system, lung cancer, or non-malignant respiratory disease. The smaller numbers of the workers in the maintenance cohort precluded any more in-depth analyses; however, detailed analyses were conducted on the production workers subcohort.

Among the subcohort of production workers, a total of 149 deaths occurred whereas 165.6 deaths were expected (table 6). The number of deaths from

Table 6 Cause-specific deaths among the subcohort of mineral wool production workers

\begin{tabular}{|c|c|c|c|c|c|c|}
\hline Cause of death & $I C D A^{*}$ & Observed deaths & Expected deaths & $S M R$ & $p$ value $^{25}$ & $\begin{array}{l}\text { Appropriate } 90 \% \\
\text { confidence limits on } \\
\text { the } S M R^{25}\end{array}$ \\
\hline $\begin{array}{l}\text { Malignant neoplasms } \\
\text { Digestive system } \\
\text { Bronchus and lung } \\
\text { Other and unspecified }\end{array}$ & $\begin{array}{l}140-205 \\
150-159 \\
162-163 \\
140-149,156 \mathrm{~B}, 165 \\
170-205\end{array}$ & $\begin{array}{r}27 \\
12 \\
7 \\
8\end{array}$ & $\begin{array}{r}29 \cdot 0 \\
9 \cdot 4 \\
8 \cdot 0 \\
11 \cdot 6\end{array}$ & $\begin{array}{r}93 \\
128 \\
88 \\
69\end{array}$ & $\begin{array}{l}0 \cdot 37 \\
0 \cdot 24 \\
0 \cdot 45 \\
0 \cdot 18\end{array}$ & $\begin{array}{l}(66-128) \\
(74-207) \\
(41-164) \\
(34-124)\end{array}$ \\
\hline $\begin{array}{l}\text { Diseases of central } \\
\text { nervous system } \\
\text { Diseases of heart } \\
\text { Non-malignant respiratory }\end{array}$ & $\begin{array}{l}330-334,345 \\
400-468\end{array}$ & $\begin{array}{l}14 \\
77\end{array}$ & $\begin{array}{l}12 \cdot 6 \\
74 \cdot 9\end{array}$ & $\begin{array}{l}111 \\
103\end{array}$ & $\begin{array}{l}0 \cdot 38 \\
0 \cdot 40\end{array}$ & $\begin{array}{l}(67-174) \\
(84-124)\end{array}$ \\
\hline $\begin{array}{l}\text { disease } \\
\text { Influenza, pneumonia, }\end{array}$ & $470-527$ & 6 & $8 \cdot 8$ & 68 & $0 \cdot 23$ & $(30-135)$ \\
\hline $\begin{array}{l}\text { bronchitis } \\
\text { Other respiratory disease } \\
\text { Residual causes, unknown }\end{array}$ & $\begin{array}{l}470-502 \\
510-527\end{array}$ & $\begin{array}{r}1 \\
6 \\
25\end{array}$ & $\begin{array}{r}5 \cdot 0 \\
3 \cdot 8 \\
40 \cdot 3\end{array}$ & $\begin{array}{r}\overline{158} \\
62\end{array}$ & $\begin{array}{l}- \\
0 \cdot 18 \\
0 \cdot 005\end{array}$ & $\begin{array}{l}- \\
(69-312) \\
(43-87)\end{array}$ \\
\hline Total & & 149 & $165 \cdot 6$ & 190 & $0 \cdot 10$ & $(78-103)$ \\
\hline
\end{tabular}

*7th Revision of International Lists of Disease and Causes of Death, adapted. 
Table 7 Deaths by latency from selected causes of death among the subcohort of rock and slag mineral wool production workers

\begin{tabular}{|c|c|c|c|c|c|c|c|c|c|}
\hline \multirow[t]{2}{*}{ Period of latency (years) } & \multicolumn{3}{|c|}{$\begin{array}{l}\text { Digestive cancer (ICDA 150- } \\
\text { 159) }\end{array}$} & \multicolumn{3}{|c|}{ Lung cancer (ICDA 162-163) } & \multicolumn{3}{|c|}{$\begin{array}{l}\text { Non-malignant respiratory } \\
\text { disease* (ICDA 510-527) }\end{array}$} \\
\hline & Obs & $\operatorname{Exp}$ & $S M R$ & Obs & $\operatorname{Exp}$ & $S M R$ & Obs & Exp & $S M R$ \\
\hline$<10$ & - & 0.8 & - & - & 0.4 & - & 0 & 0.2 & - \\
\hline 10-19 & 1 & 1.9 & - & 1 & $1 \cdot 1$ & - & 1 & 0.5 & - \\
\hline$\geqslant 20$ & 11 & $6 \cdot 7$ & 164 & 6 & $6 \cdot 5$ & 92 & 5 & $3 \cdot 1$ & 161 \\
\hline Total & 12 & $9 \cdot 4$ & 128 & 7 & $8 \cdot 0$ & 88 & 6 & $3 \cdot 8$ & 158 \\
\hline
\end{tabular}

*After excluding influenza, bronchitis, and pneumonia.

Table 8 Deaths by duration of work from selected causes of death among the subcohort of rock and slag mineral wool production workers

\begin{tabular}{|c|c|c|c|c|c|c|c|c|c|}
\hline \multirow[t]{2}{*}{ Duration of work (years) } & \multicolumn{3}{|c|}{$\begin{array}{l}\text { Digestive cancer (ICDA 150- } \\
\text { 159) }\end{array}$} & \multicolumn{3}{|c|}{ Lung cancer (ICDA 162-163) } & \multicolumn{3}{|c|}{$\begin{array}{l}\text { Non-malignant respiratory } \\
\text { disease* }^{*}(I C D A \text { 510-527) }\end{array}$} \\
\hline & $O b s$ & $\operatorname{Exp}$ & $S M R$ & Obs & $\operatorname{Exp}$ & $S M R$ & Obs & $\operatorname{Exp}$ & $S M R$ \\
\hline $\begin{aligned}< & 10 \\
& 10-19 \\
\geqslant & 20\end{aligned}$ & $\begin{array}{l}3 \\
4 \\
5\end{array}$ & $\begin{array}{l}4 \cdot 9 \\
3 \cdot 0 \\
1 \cdot 5\end{array}$ & $\begin{array}{r}61 \\
134 \\
333\end{array}$ & $\begin{array}{l}1 \\
4 \\
2\end{array}$ & $\begin{array}{l}4 \cdot 4 \\
2 \cdot 1 \\
1 \cdot 5\end{array}$ & $\frac{-}{-}$ & $\begin{array}{l}3 \\
1 \\
2\end{array}$ & $\begin{array}{l}2 \cdot 0 \\
1 \cdot 1 \\
0 \cdot 7\end{array}$ & - \\
\hline Total & 12 & $9 \cdot 4$ & 128 & 7 & 8.0 & 88 & 6 & $3 \cdot 8$ & 158 \\
\hline
\end{tabular}

*After excluding influenza, bronchitis, and pneumonia.

Table 9 Deaths from digestive cancer among white male rock and slag mineral wool production workers

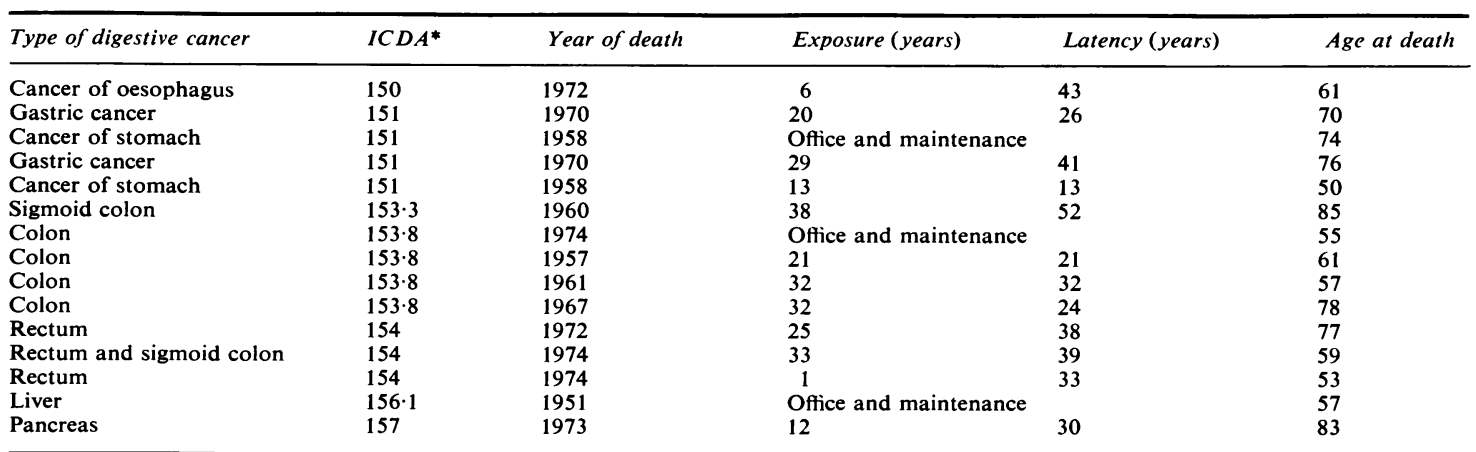

*7th Revision of International Classification of Diseases, adapted.

cancer of the digestive system was slightly increased as was the number of deaths from non-malignant respiratory disease after excluding influenza and pneumonia.

In the county where the plant is located, white male mortality rates for cancers of the digestive and respiratory systems are lower than those of the entire United States by $19 \%$ and $6 \%$ respectively. ${ }^{26}$ Thus the number of deaths expected to occur among study cohort members would have been lower and the SMR higher if county mortality rates had been used rather than the general US rates.

The ratios of observed to expected deaths due to cancer of the digestive system increased with years since first production work (latency) and with duration of employment (tables 7, 8). SMRs are not strictly comparable, but their increasing trend with duration of exposure, although based on small numbers, suggests dose-response and is consistent with an occupational aetiology. No such trend was observed for the SMRs for lung cancer. The excess of non-malignant respiratory disease seemed to be most evident after 20 years' latency.

Tables 9 and 10 list all deaths from cancer of the digestive system and non-malignant respiratory disease. The underlying cause of death and year of death as indicated on each death certificate is listed. A careful review of the death certificates for cancer of the digestive system showed that the increases were not restricted to any particular site. 
Table 10 Deaths from non-malignant respiratory disease among white men employed in a rock and slag mineral wool production and manufacturing plant

\begin{tabular}{|c|c|c|c|c|c|}
\hline $\begin{array}{l}\text { Type of non-malignant } \\
\text { respiratory disease }\end{array}$ & $I C D A^{*}$ & Year of death & Exposure (years) & Latency (years) & Age at death \\
\hline Emphysema & $527 \cdot 1$ & 1969 & 34 & 52 & 75 \\
\hline Emphysema & $527 \cdot 1$ & 1961 & 16 & 18 & 43 \\
\hline Emphysema & $527 \cdot 1$ & 1972 & 15 & 30 & 79 \\
\hline Emphysema & $527 \cdot 1$ & 1962 & 19 & 29 & 80 \\
\hline Pulmonary emphysema & $527 \cdot 1$ & 1966 & 31 & 38 & 63 \\
\hline \multicolumn{6}{|l|}{ Chronic obstructive } \\
\hline pulmonary disease & $527 \cdot 1$ & 1973 & 34 & 45 & 72 \\
\hline Emphysema & $527 \cdot 1$ & 1969 & Office & & 69 \\
\hline Pulmonary emphysema & $527 \cdot 1$ & 1970 & Office and mainte & & 61 \\
\hline
\end{tabular}

7th Revisicn of International Classification of Diseases, adapted.

\section{Discussion and interpretation}

Owing to the small number of deaths, none of these results was statistically significant. In the subcohort with the highest severity of exposure (production), however, the raised SMRs were associated with both duration of employment and latency for cancer of the digestive system and non-malignant respiratory disease.

Like most other cancers, those of the digestive system probably have a multifactorial aetiology. Risk factors such as $\operatorname{diet}^{27}$ and ethnicity ${ }^{28}$ have been implicated in various studies. Unfortunately, diet could not be investigated; however, the low county death rate for cancer of the digestive system would tend to argue against local diet or other indigenous factors being responsible for the excess in this study. A review of the death certificates for cancer of the digestive system did not show any Asian surnames or foreign born. In fact, all but one worker had been born in the Midwest.

A few occupational exposures have been associated with cancer of the digestive system. In particular, asbestos exposure has been implicated. ${ }^{29}$ Only two workers in the study cohort, however, were known to have been exposed to asbestos at the plani, and neither died from cancer of the digestive system.

Under recent conditions only $3 \%$ of all airborne mineral wool fibres in this plant were estimated to have been deposited in the respiratory tract. Nevertheless, it was estimated that roughly $60 \%$ of the fibres from the current spinning process and somewhat fewer of the fibres from the steam-blown process would be cleared to the gastrointestinal tract, suggesting a biological plausibility for the observed increase in cancer of the digestive system. ${ }^{16} 17$

The cause-specific excess risks of death from cancer of the digestive system and non-malignant respiratory disease beyond 20 years of latency are based on small numbers and are not statistically significant. Cigarette-smoking patterns of the workers were not assessed and could have contributed to the excesses of non-malignant respiratory disease found, although the association of colonic cancer with tobacco use has been reported ${ }^{30}$ to be weak. Since no excess of deaths from lung cancer was found in these data, however, cigarette smoking is unlikely to account for these excesses. Because these causes of death have been previously associated with exposures to mineral wool, ${ }^{14}$ and other types of man-made fibres ${ }^{31}$ as well as asbestos fibres ${ }^{12}$ after long latency periods, and because these were the only two causes of death raised with increased latency and duration of employment, an occupational aetiology must be considered.

Seidman et $a^{32}$ recently reported that generally for asbestos workers, the lower the dose the longer it takes for adverse mortality experience to become evident because of both a longer latent period and the smaller magnitude of the adverse mortality. Our study, and two others, ${ }^{19} 20$ have shown that mineral wool production workers received very light exposures compared with what is known of historic asbestos exposure levels. The mortality experience of our cohort of rock and slag mineral wool production workers is not inconsistent with Seidman's findings.

In view of the consistency of the findings of this present study and those of the others mentioned above, the possibility that rock and slag mineral wool is associated with carcinogenicity or non-malignant respiratory disease cannot be ruled out yet. Therefore further follow-up of this cohort will be maintained. In addition, it is urged that inhalation experimental studies that examine the relationships of fibre size and type to health effects be planned and conducted.

We appreciate the efforts of the many individuals of the industry-wide studies branch who have contributed to this research. A special thanks to Richard Lemen for his continuing encouragement, advice, and guidance; to Joseph Wagoner for his advice and guidance; to Dave Bayliss and Bruce Gehring for starting the project; to Ralph Zumwalde, Ken Wallingford, Bob Phillips, and Chuck Murphy for their help on the industrial hygiene survey of the study plant; to the clerical and secretarial staff of the biometry section for their extensive follow-up work 
and project support; to Mike Alexander, Jim Henry, Pat Martin, Carol Anderson, and Leslie Showes of the Southwestern Ohio Regional Computer Center Staff; to all the Federal, State, and local offices who helped in the vital status follow-up; to Gary Marsh for his assistance in obtaining 941 forms, and, finally, to the management of the corporation, union, and local plant for their help during the study.

Funding for this project was provided by the Environmental Protection Agency under the Interagency Energy/Environment Agreement (EPA-IAGDS-E773).

\section{References}

${ }^{1}$ World Health Organisation, IARC Working Group on the Evaluation of the Carcinogenic Risk of Chemicals to Man. Asbestos. Lyon: IARC, 1977. (IARC Monograph, No 14.)

${ }^{2}$ US Department of Health, Education and Welfare, PHS, CDC, NIOSH. Revised recommended asbestos standard. Washington, DC: US Government Printing Office, 1976. (DHEW (NIOSH) pub No 77-169.)

${ }^{3}$ Thoenen JR. Mineral wool. Washington, DC: US Department Interior, Bureau of Mines, 1939. (IC 6984R.)

${ }^{4}$ Rarick RD, Ault CH. Mineral wool-historic Indiana industry. Outdoor Indiana 1977;42:29-33.

${ }^{5}$ US DHEW, PHS, CDC. Proceedings, 1976, NIOSH symposium on occupational exposures to fibrous glass. Washington, DC: US Government Printing Office, 1976. (DHEW (NIOSH) pub No 76-151.)

${ }^{6}$ US DHEW PHS, CDC. Criteria for a recommended standard on occupational exposure to fibrous glass. Washington, DC: US Government Printing Office, 1977. (DHEW (NIOSH) pub No 77-152.)

7 Wagner JC, Berry G, Skidmore JW. Studies of the carcinogenic effects of fiber glass of different diameters following nitra pleura inoculation in experimental animals. Proceedings NIOSH symposium, occupational exposures to fibrous glass. Washington, DC: US Government Printing Office, 1974. (DHEW (NIOSH) pub No 76-151: 193-197.)

${ }^{8}$ Pott F, Huth F, Friedrichs KH. Results of animal carcinogenesis studies after application of fibrous glass and their implications regarding human exposure. Proceedings NIOSH symposium on occupational exposures to fibrous glass. Washington, DC: US Government Printing Office, 1974. (DHEW (NIOSH) pub No 76-151: 183-191.)

${ }^{9}$ Stanton MF, Layard M, Tegeris A, Miller E, May M, Kent E. Carcinogenicity of fibrous glass: pleural response in the rat in relation to fiber dimension. $J$ Natl Cancer Inst 1977; 58:587-603.

${ }^{10}$ Wagner JC, Berry G, Hill RJ, Munday DG, Skidmore JW. Animal experiments with man-made mineral fibres. Biologic effects of mineral fibres. Vol 1. Lyon: IARC, 1979:361-2.

${ }^{11}$ Tilkes F, Beck EG. Comparison of the length-dependent cytotoxity of inhalable asbestos fibres and their oncogenic potential. Biologic effects of mineral fibres. Vol 1. Lyon: IARC, 1979:475-84.

12 Johnson HF, Wagner JC. A study by electron microscopy of the effects of chrysotile and man-made fibers on rat lungs. Biologic effects of mineral fibres. Vol 1. Lyon: IARC, 1979:293-304.

${ }^{13}$ McConnell WJ, Lanza RI. (Chest study of mineral wool workers for Metropolitan Life Insurance Company), cited in Carpenter JL, Spolyar LW. Negative chest findings in a mineral wool industry. J Indiana State Med Assn 1945;38:389-90.

${ }^{14}$ Enterline PE, Marsh GM. Mortality of workers in the man-made mineral fiber industry. Biologic effects of mineral fibres. Vol 2. Lyon: IARC, 1979:965-72.

${ }^{15}$ Zumwalde RD, Dement JM. Review and evaluation of analytical methods for environmental studies of fibrous particulate exposures. Washington, DC: US Government Printing Office, 1977. (DHEW (NIOSH) pub No 77-204.)

${ }^{16}$ Harris JRL. Aerodynamic considerations; what is a respirable fiber of fibrous glass? In: Proceedings, $\mathrm{NIOSH}$ symposium on occupational exposures to fibrous glass. Washington DC: US Government Printing Office, 1974. (DHEW (NIOSH) pub No 76-151.)

17 Dement JM, Harris RL. Estimates of pulmonary and gastrointestinal deposition for occupational fiber exposures. Washington DC: US Government Printing Office, 1979. (DHEW (NIOSH) pub No 79-135.)

${ }^{18}$ Carpenter JC, Spolyar LW. Negative chest findings in a mineral wool industry. J Indiana State Med Assn 1945; 38:389-90.

${ }^{19}$ Esmen NA, Hammad YY, Corn M, et al. Exposure of employees to man-made mineral fibers: mineral wool production. Environ Res 1979;15:262-77.

${ }^{20}$ Esmen N, Corn M, Hammad Y, Whittier D, Kotsko N. Summary of measurements of employee exposure to airborne dust and fiber in sixteen facilities producing man-made mineral fibers. Am Ind Hyg Assoc J 1979;40: 108-17.

${ }^{21}$ Fowler DP. Industrial hygiene surveys of occupational exposures to mineral wool. Washington, DC: Government Printing Office, 1978. (NIOSH technical report, DHHS (NIOSH) pub No 80-135.)

${ }^{22}$ Cutler SJ, Ederer F. Maximum utilization of the life table method in analyzing survival. J Chron Dis 1958;8:699709.

${ }^{23}$ Bailar JC III, Ederer F. Significance factors for the ratio of a Poisson variable to its expectation. Biometrics $1964 ; 60$ : 639-42.

${ }^{24}$ Marsh GM, Enterline PE. A method for verifying the completeness of cohorts used in occupational mortality studies. JOM 1979;21:665-70.

${ }^{25}$ Rothman KJ, Boice JD Jr. Epidemiologic analysis with a programmable calculator. Washington, DC: Government Printing Office, 1979. (DHEW pub No (NIH) 79-1649.)

${ }^{26}$ Mason TJ, McKay FW. US cancer mortality by county: 1950-69. Washington, DC: US Government Printing Office, 1973. (DHEW pub No (NIH) 74-615.)

${ }^{27}$ Burkitt D. Epidemiology of cancer of the colon and rectum. Cancer $1971 ; 28: 3-13$.

${ }^{28}$ Segi M, Kurihara M. Trends in cancer mortality for selected sites in 24 countries, 1950-9. Sendai, Japan: Department of Public Health, 1963.

${ }^{29}$ Selikoff IJ. Lung cancer and mesothelioma during prospective surveillance of 1249 asbestos insulation workers 1963-74. Ann NY Acad Sci 1976;271:448-56.

${ }^{30}$ Correa P, Haenszel W. The epidemiology of large bowel cancer. In: Klein G, Weinhouse S, eds. Advances in cancer research. New York: Academic Press, 1977;26: 1-141.

${ }^{31}$ Bayliss DL, Dement J, Wagoner JK, Blejer HP. Mortality patterns among fibrous glass production workers. Ann NY Acad Sci 1976;271:345-52.

${ }^{32}$ Seidman H, Selikoff IJ, Hammond EC. Short-term asbestos work exposure and long-term observation. Ann NY Acad Sci 1979;330:61-90. 